\title{
Research of State for Warning Method under Power System Peak Load Mode
}

\author{
Kai Yan ${ }^{a}$, Bin Li ${ }^{b}$, Shihui Yang ${ }^{c}$, Fangfang Duan ${ }^{d}$ \\ State Grid Henan Electric Power Company Luoyang Power Supply Company, \\ Luoyang 471000, China \\ a luoyangdidiao@sina.com, b 1015903240@qq.com
}

Keywords: Peak load, the state of alert, dispatch

\begin{abstract}
In the actual power system, the blackouts or voltage collapse accidents may happen frequently when the peak load are calming up steeply. If we can't propose any effective methods to control the situation before these accidents spreading, it will obviously cause power system's large blackout. That is the question which the paper has researched on. Based on the sand pile model, using the method of flow calculation and the venin equivalent of the state power grid peak load mode were estimated for grid dispatching personnel to provide a reference for grid security, stability, economic operation has significance.
\end{abstract}

\section{Introduction}

With the continuous improvement in recent years, the development of technology and the people's living standards, the power system as a major system of energy supply, industry and agriculture as well as carrying security work life energy. Therefore, the security and stability of the power system is crucial. The incidents of power system at home and abroad continue to occur in recent years, and the defects in the peak hours of electricity have people about the safety of the power system to worry about.

Natural disasters and external damage is difficult to expect, and the power grid load operation, especially in the situation is to be expected throughout the grid during the peak period and real-time adjustments. In the course of the grid load operation, especially in peak periods, critical state grid state sand pile model has many similarities: similar growth sand distribution grid load growth randomness in the geographical and time; sand heap model small avalanches trip event similar to the grid; overall avalanches and large chain similar trip and voltage collapse. Visible sand pile model is introduced to analyze the state of the power grid is reasonable. Based on the sand pile model, using the method of flow calculation and the venin equivalent of the state power grid peak load mode were estimated for grid dispatching personnel to provide a reference for grid security, stability, economic operation has significance.

\section{Theoretical Analysis Thevenin Equivalent Peak Mode}

Grid during peak run mode could cause a series of accidents, the study of peak load more and more people's attention. Since the load of each constituent in the electricity area over a period of time will not change much, so load change especially in peak load variations are to follow the law. By processing the historical load data of the area, grasp the common historical relationship between the throttle and then consider changes in the weather conditions, peak load mode can be established to realize the peak load forecasting, supply network state analysis. In the operating state above the peak mode, the load pressure of the grid is rapidly increasing, and when some of the nodes of the load is too large, it may cause node voltage instability, if you cannot get timely control, there will be large-scale grid The voltage collapse accident, this is what we do not want to see. Thevenin equivalent theory that is the problem with respect to monitoring node voltage raised. In the case of peak load change, Thevenin equivalent parameter provides an effective means for real-time analysis to determine the grid voltage collapse warning. 
In the load mode with the same characteristics, there is a strong historical correlation and regularity. Feasts are of the same nature in the same (weekdays or holidays) of the date, often having to reproduce the obvious characteristics. From the historical load data, extracted feature information of high load, the state is estimated peak load conditions.

According to the classical theory Thevenin equivalent circuit using Thevenin equivalent in the grid, the peak load in accordance with the division of solving Thevenin equivalent parameters and operating points points in the neighborhood, deduced important Thevenin equivalent parameters (Thevenin, etc. value impedance angle, Thevenin equivalent impedance mode, Thevenin equivalent voltage angles, Thevenin equivalent potential and the node equivalent impedance modulus ratio), and then for the next grid state analysis laid the foundations of mathematics.

\section{Accident Research Network Sand-pile Model}

In recent years a large grid of frequent accidents, many scholars collapse accident in-depth research on power system cascading tripping accidents and voltage. Power grid cascading failures is because power system experienced a disturbance (such as circuit breaker, power dispatch improper, demand-side load surge, etc.), the trend of redistribution lead to power some of the electrical component is too large, or some node voltage instability after these abnormal situation has not been effectively controlled grid caused. For these reasons, the use of node voltage magnitude, phase angle and amplitude of nodal admittance matrix derived voltage collapse prediction index VCPI, according to the value to reflect the possibility of change VCPI grid voltage collapse, and is suitable for both static and dynamic voltage collapse prediction. The use of some control variables, such as a combination of load voltage, generator reactive power and some other variables to establish a maximum load edge function $\lambda$, by the calculation of $\lambda$ derived optimal voltage collapse before the system can withstand the maximum load of the grid.

The Accident Research sand-pile model used in power systems is still a relatively new direction. Sand-pile model is a self-organized criticality physical model, time, and size in critical condition collapse happens is the probability of an event, at this point, with the occurrence of a grid accident has great similarities. By utilizing this property will be able to apply the idea of probability on the critical state of the grid is determined to enhance the power grid accident judgment timeliness.

Current status of operation under normal working conditions can be seen as equilibrium. With the increase of users, the load is constantly increasing, in some lines appeared in the case load of the grid overload trip will occur, causing a short circuit, the equivalent of small avalanches. As the load continues to increase, the power distribution system is faster change, regional power transmission capacity between users is also increasing, and some lines are likely to overload operation, which corresponds to a critical state sand-pile model. In this state, the trip appears to exit certain routes, it can cause massive chain trip or at some point voltage instability caused by the collapse of the entire network voltage.

\section{Grid Accident Early Warning Platform}

The platform can be read as needed urgent analysis of network load data to grid accident sequences are displayed as the main kernel algorithm, by calculating the input data, showing a variety of an accident under the load factor rising conditions, and can single-step analysis grid under the status of a load level for the grid provides an effective basis for decision-making.

Accident early warning platform is the use of data or historical data grid running from the peak of the RTU device collected as the original input data. Due to the amount of data grid is very large, and therefore cannot simply use the data entry manually input data using a computer, it must be obtained, and the new data entry on the content or format may not meet the requirements of computing platform, so after the data into the database before finishing.

After the data into the database, you can connect to the database platform. Data call include: branch data (including branches of resistance, reactance, admittance, transformer turns ratio statistics branch also needs and determine the relationship between nodes), load node data 
(including node type, node active power, reactive power node power), the generator node data (including node types, generator active power output, the generator reactive power). After the platform and database connection data can be intuitively operated and maintained on the run accident early warning platform interface. In the process of algorithm analysis, this platform rises automatically load simulation and real-time reporting of events (leg trip, flow calculation does not converge, voltage collapse), and after the incident, the system load level. Through a set of input data repeatedly experiment, you will find a slightly different result; it introduced the results of probability in the algorithm. As mentioned before, which is a critical operating state of Grid has a very practical significance. If you want to do after an accident more comprehensive analysis, it can also manually load level calculated at the time of the trend in which the size and the time of the accident according to Thevenin parameters, so that a more comprehensive analysis of the specific accident.

Data acquisition and data processing work entered into the database in the absence of even running situation requires outside platform, ie data collected should be collated again introduced into the early warning platform, we need to design the future in this respect further improved. Accident analysis and decision support platform in-house accident analysis algorithm based on function, so the basic functions of the platform front interface include: export import data, maintain the data flow computing, grid computing Thevenin equivalent parameters and grid operation state analysis.

Calculated on the basis of the trend can be simulated and analyzed the state of the grid. Power warning function is to demonstrate the power grid accident sequence algorithm program embedded implementation. Automatic calculation section, automatic load factor increase in growth to have an accident occurs, it is given in the accident log load factor reached the number of accidents which occur, and the accident has sort, making the process of the accident at a glance. When the grid load node voltage collapse incident, automatically exit operations, and give the final warning. Since automatic calculation does not give a specific trend data and Thevenin equivalent parameters for each moment, here also designed the single-step debugging. The load factor of the self-filling may want to load factor observed data, the trend will soon be the case at the moment of each node and Thevenin equivalent parameters, based on an analysis of the data, help analyze grid state change, the grid the timely dispatch provided useful supplementary strategy.

The increase of the probability of the form of grid load simulates peak load growth, the trend of the grid and the node voltage at different levels to determine. Under the premise of the convergence trend, a trip to the branch load reaches a critical edge in the form of the probability of tripping circuit, and a trip report, increasing the randomness of the accident, further determination node voltages, voltage instability entering the critical edge the node issued a warning, showing the sequence of the accident, realized the accident early warning capabilities.

\section{Summary}

In today's world of rapid economic development context, countries are increasing consumption, particularly in the case of electricity and renewed summer temperatures, and each transmission line are basically in overloaded state, once the subject line trip or node voltage is low such disturbances, it is prone to large chain tripping or voltage collapse accident. Grid accident usually does not occur at low load levels, the researchers characterized each peak load peak load mode, thus more accurately determine the peak time of the grid possible accident, peak load and peak climbing speed segment. These parameters make the grid peak research more practical significance as raw data for further research.

\section{Reference}

[1] Peik-Herfeh M, Seifi H, Sheikh-El-Eslami M K. Decision making of a virtual power plant under uncertainties for bidding in a day-ahead market using point estimate method[J]. International Journal of Electrical Power \& Energy Systems, 2013, 44(1):88-98. 
[2] Hamada M M, Wahab M A A, Hemdan N G A. Simple and efficient method for steady-state voltage stability assessment of radial distribution systems[J]. Electric Power Systems Research, 2010, 80(2):152-160.

[3] XU Jianyuan;LI Jiajue;LIN Xin;ZHU Yu;LIU Jinsong;WANG Gang;Liaoning Province Key Lab of Power Grid Safe Operation and Monitoring (Shenyang University of Technology);Electric Power Research Institute of State Grid Liaoning Electric Power Co, ; L. A Power Balance Control Method for Distributed Generation Island With Multi-margin Operation[J]. Proceedings of the Csee, 2014.

[4] Asadi M, Jalilian A. An improved current control method of shunt active power filter based on state-space variables under asymmetrical and non-sinusoidal conditions[C]// Power Engineering and Optimization Conference (PEOCO), 2011 5th International. IEEE, 2011:285 - 290.

[5] Almeida M C, Asada E N, Garcia A V. A Numerical Method for Finding Spanning Trees in Power System State Estimation[C]// Power System Technology, 2006. PowerCon 2006. International Conference on. IEEE, 2006:1 - 6.

[6] Singh, B., \& Singh, B. (2011). Applications of facts controllers in power systems for enhance the power system stability: a state-of-the-art.International Journal of Reviews in Computing. 